\title{
FORMULATION AND EVALUATION OF WOUND HEALING GEL OF WHITE LEADTREE (LEUCAENA LEUCOCEPHALA (LAM.) DE WIT.) LEAVES EXTRACT
}

\section{EVY FENNY VERONICA*, RINI DWIASTUTI}

\author{
Faculty of Pharmacy, Sanata Dharma University, Yogyakarta, Indonesia
}

*Email: evyfenny@gmail.com

Received: 20 May 2021, Revised and Accepted: 14 Oct 2021

\begin{abstract}
Objective: The aim of this research is to formulate and evaluate the wound healing gel of Leucaena leucocephala leaves extract.

Methods: In this research, the extract of Leucaena leaves was formulated into wound healing gel by using a variation of the concentration of Carbopol as a gelling agent and Propylene glycol as a humectant. Afterward, the gel's physical properties ( $\mathrm{pH}$, viscosity, spreadability), stability, and sterility were tested. The wound healing activity was evaluated by making excision wounds on the Wistar Albino rat's back, and then the gels were applied to the wound every day. The wound's size was measured and counted as the percentage of wound closure.

Results: The result showed that Formula 4 (contains $1.5 \%$ of Carbopol and 12\% of Propylene glycol) has the best physical characteristics and wound healing activity. Formula 4 showed $100 \%$ wound closure on the $11^{\text {th }}$ day of the treatment, while the negative control only reached $49.12 \%$.
\end{abstract} The statistical parameter with the $p$-value $<0.05$ stated that they are significantly different.

Conclusion: This research demonstrated that gel with Leucaena leaf extract has good physical characteristics, and it can significantly improve the wound healing process.

Keywords: Leucaena leaves, Gel, Wound healing, Gelling agent, Humectant

(C) 2022 The Authors. Published by Innovare Academic Sciences Pvt Ltd. This is an open access article under the CC BY license (https://creativecommons.org/licenses/by/4.0/) DOI: https://dx.doi.org/10.22159/ijap.2022v14i1.42126. Journal homepage: https://innovareacademics.in/journals/index.php/ijap

\section{INTRODUCTION}

Wound, an incident often experienced by humans in daily activities, is simply defined as the broken of skin tissue [1]. Many factors can cause the damage of skin tissue, such as physical friction or high temperature that disrupts the arrangement of epithelial or mucosa cells on the skin [2]. The wound healing process is an essential process with which the skin's function as the body protection means can be restored immediately. The wound healing process consists of several stages started from inflammation, a proliferation that includes epithelialization, angiogenesis, and skin remodeling [3]. During those complex processes, it is necessary to maintain the wound's sterility, protect the wound from contamination that can cause infection, prevent dehydration (moisture is needed for the new tissue arrangement), and also absorb or eliminate the wound exudate [4].

According to the Food and Drug Administration (FDA), preparations for wound healing, or also known as wound dressing combined with drugs, are divided into three categories: the wound dressing in solid forms, preparation of semisolid (ointments, creams, gels), and wound cleaning fluid [5]. The application of appropriate dosage forms and formulations in the wound therapeutic is required to accelerate the wound healing process. One of the suitable dosage forms for this purpose is a gel. A gel is a rigid structure formed by a cross-linking network of three dimensions that swells in an appropriate solvent; when the solvent is water, it is known as hydrogel [6]. The high water content in the gel formula is suitable for the environment needed for wound healing. It creates a moist environment and absorbs wound exudates to accelerate the wound healing process [5]. Besides, the gel can provide a cool sensation when applied to the injured skin so that it can reduce the pain experienced by the patient. Further, it is also easily applied and removed from the skin [7].

There are so many topical wound healing products on the market. Most of them contain active pharmaceutical ingredients that belong to antiseptics and antimicrobials categories, such as Neomycin, Mupirocin, Povidone Iodine, Hydrogen Peroxide, and Bacitracin [7] The use of antimicrobials in the medical world lately starts to cause debates due to the significant risk of the bacteria resistance event [8]. It triggers many kinds of research that focus on searching for new drug materials that can be used as wound healing agents. One section of the searches involves the use of natural wealth. Spread in nature, many plants have wound healing activity. One of the plants is the White Leadtree (Leucaena leucocephala), or also known as Petai Cina in Indonesia. Leucaena leaf is traditionally used to heal wounds by being chewed or chopped, then placed on the injured skin until it is healed [9]. Leucaena leaf has some pharmacology effects, such as an anti-inflammatory and antibacterial activity that relates to the wound healing process [10]. Several studies have proven the effectiveness of this plant in the wound healing process. The ethanol extract of Leucaena leaves has shown its ability to accelerate wound closure [11] Research by Fitrian (2018) proves that the gel of Leucaena leaves extract at $15-45 \%$ concentration can heal the incision wound in rats. In other research, Leucaena leaves extract that is formulated in ointment preparation at $20 \%$ concentration is proven to accelerate wound healing in rats [12].

In the pharmaceutical formulation design, the compatibility between the active ingredients and other excipients in the dosage form should be considered. Ethanolic extract has good compatibility with water; so in this research, the ethanolic extract of Leucaena leaf is formulated as hydrogel. The urgency of this research is to find a natural ingredient that can be used as wound healing medicine and to formulate the ingredient into the dosage form that fulfills the pharmaceutical aspects, such as efficacy, safety, and quality. In this study, the formulations of wound healing gel preparation using Leucaena leaves extract with various concentrations of gelling agent (Carbopol 940) and humectant (Propylene glycol) were done. The evaluation was carried out on the physical properties of the gel, the stability of the gel, and the wound healing activity of each formula, in order to study the characteristics of the gel-based on the formulation consideration.

\section{MATERIALS AND METHODS}

\section{Materials}

Leucaena leucocephala leaves, Ethanol 96\%, Propylene glycol (Pharmaceutical grade), Carbopol ${ }^{\circledR 940}$ (Pharmaceutical grade), Triethanolamine (Pharmaceutical grade), Methylparaben (Pharmaceutical grade), distilled water, 12 albino adult male Wistar rats (weight 200-300 g), and Bioplacenton ${ }^{\circledR}$ gel. 


\section{Preparation of Leucaena leaves extract}

The Leucaena leaves were harvested from the Botanical Garden of the Faculty of Pharmacy, Sanata Dharma University, Yogyakarta, Indonesia. The determination of the plant from which the harvest was done had been conducted by the legal determinator of the Faculty of Pharmacy, Sanata Dharma University, with specimen number 003/IKTO/far-USD/II/13. The harvested leaves were washed under flowing water to remove all the dirt. Then, the leaves were dried naturally until they were thoroughly dried up and easily crushed when squeezed. The dried Simplicia was crushed using a blender and sieved with a mesh 40 sieve to obtain powders with a uniform size. A total of 25 grams of Leucaena leaves powder was macerated with $500 \mathrm{ml}$ of a mixture of distilled water: ethanol $96 \%$ (1:1) for three days at room temperature. The extract was then filtered with the help of a vacuum pump, and the filtrate was macerated again with $500 \mathrm{ml}$ 96\% ethanol for $1 \mathrm{~d}$, then filtered again. Both filtrate liquids were mixed and concentrated with
Vacuum Rotary Evaporator, and then the extract was stored in tightly-sealed containers at room temperature for the next step.

\section{Formulation of gel}

The gel was prepared using the formula written in table 1; Carbopol as a gelling agent, propylene glycol as a humectant, triethanolamine as a $\mathrm{pH}$ neutralizer, and methylparaben as a preservative are the commonly used excipients in pharmaceutical gel formulations, especially for topical usage. Carbopol 940 was swelled in the distilled water, and then left overnight until it was perfectly swollen. Propylene glycol and methylparaben were added to the mixture and then stirred using a mixer. Triethanolamine was added slowly until the $\mathrm{pH}$ of the gel base reached the neutral point $( \pm 7.0)$, then it was stirred until it was forming a homogeneous base [13]. The gel base, Leucaena leaves extract, and distilled water were then sterilized using an autoclave at a temperature of $121^{\circ} \mathrm{C}$ for 15 min. Under the LAF (Laminar Air Flow), Leucaena leaves extract and the rest of the distilled water were added into the gel base and stirred with a mixer for $1 \mathrm{~min}$.

Table 1: Gel formula

\begin{tabular}{|c|c|c|c|c|}
\hline Materials & F1 (\%w/w) & F2 (\%w/w) & F3 (\%w/w) & F4 (\%w/w) \\
\hline Leucaena leaves extract & 6 & 6 & 6 & 6 \\
\hline Carbopol 940 & 1 & 1.5 & 1 & 1.5 \\
\hline Propylene glycol & 10 & 10 & 12 & 12 \\
\hline Methyl paraben & 0.1 & 0.1 & 0.1 & 0.1 \\
\hline Triethanolamine (TEA) & \multicolumn{4}{|c|}{ Until the $\mathrm{pH}$ of the gel base is neutral } \\
\hline Distilled water & Ad $100 \%$ & Ad $100 \%$ & Ad $100 \%$ & Ad $100 \%$ \\
\hline
\end{tabular}

\section{Physical properties and physical stability test of gel}

\section{Organoleptic and pH}

An organoleptic test was carried out by observing the odor and color of the gel $48 \mathrm{~h}$ after the preparation. The measurement of $\mathrm{pH}$ was done using universal $\mathrm{pH}$ indicators ( $\mathrm{pH}$ stick) by putting the stick into the preparations and then comparing the color appearing in the indicator with standard color [14].

\section{Spreadability test}

The measurement of the gel's spreadability was carried out $48 \mathrm{~h}$ after preparation. For this test, 1 gram of the gel was placed in the center of a round scaled glass plate. On top of the gel, a round glass and a weight with the combined weight of 125 grams were placed. The condition was preserved for 1 minute, and then the diameter of the gel's spread was recorded [15].

\section{Viscosity test}

The viscosity test was done twice: $48 \mathrm{~h}$ after gel preparation and 1 mo after the gel was put in the storage. The viscosity of each formula was tested using Viscotester Rion series VT 04. The size of the rotor used was the number 2 [16].

\section{Sterility test}

The sterility test was carried out using the spread plate technique. A small amount of the gel was taken and placed in the Nutrient Agar (NA) medium, which was put on a petri dish and flattened with the help of an aseptic spreader rod. The petri dish was incubated for \pm 24 h. After that, it was observed to indicate whether colonies of bacteria in the medium were present [17].

\section{Wound healing activity test}

This procedure has been granted the Ethical Clearance approval from the Medical and Health Research Ethics Committee (MHREC) Gadjah Mada University, Yogyakarta, Indonesia (Approval Number: $\mathrm{KE} / \mathrm{FK} / 378 / \mathrm{EC}$ ). The wound healing activity test was done using a model of wound excision. Six albino adult male Wistar rats (weight 200-300 g) were divided randomly into six groups; one rat in each group. The back of each rat was injured and prepared after being cleaned. The skin area with a diameter of $\pm 1 \mathrm{~cm}$ on the back of each rat was cut using a sterile scalpel and scissors after the rats were anesthetized. Group 1 was given Bioplacenton ${ }^{\circledR}$ gel (positive control), group 2 was not given any treatment (negative control), while groups 3, 4, 5, and 6 were given Leucaena leaves extract formula 1-4 respectively, once daily. The wounds that were treated with gel were dressed with sterile gauze and bandage. On each day after the treatment, the wound diameter was measured and the gel was reapplied until the wound was closed entirely. The repetitions were carried out three times by giving three wounds to each rat. Contraction of the wound was measured and presented in the daily percentage of wound reduction $[18,19]$.

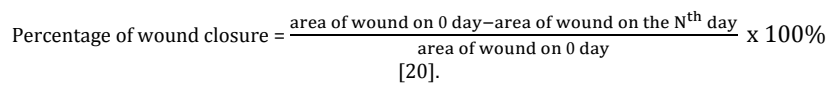

\section{RESULTS AND DISCUSSION}

\section{Formulation consideration}

The selection of each material and excipient used in the formula should be carefully considered to ensure that all of them can produce viable efficacy of the drug. In this research, ethanol and distilled water are used as the diluents in the extraction process. The election is taken with the consideration of the solubility of the active constituents having wound healing activity existed in Leucaena leaf (tannin, saponin, and flavonoid) [21]. Tannin and flavonoid of the Leucaena leaf were found in the non-polar extract solvent (ethanol), as the saponin was found in the polar solvent (water) [22].

Wound healing is a complex process, and along that process, it is important to keep the wound area sterile, free from contamination and bacteria that can cause infection, and hydrated [4]. The recent development in wound management found that a moist environment would accelerate the wound healing process, especially in the reepithelization process [23]. Carbopol, when dispersed into water and alkalized, will form a rigid three-dimensional network that has the ability to absorb water and to retain the water content absorbed in its network [24]. Propylene glycol is a humectant that has a vital role in topical preparations by maintaining skin moisture and increasing water absorption from the epidermis to the deeper parts of the skin (the dermis) [25]. As water considerably facilitate microbial growth, in order to prevent this happening in the formulation of the hydrogel that contains more than $80 \%$ of water, methylparaben as a preservative is added in the formula. Thus, the wound will not be contaminated or infected, and the infection will not inhibit the wound healing process. 


\section{Physical properties and physical stability test of gel}

\section{Organoleptic and $\mathrm{pH}$}

The physical appearance (organoleptic) of a wound-healing preparation is an important factor that needs to be considered. Specifically, the organoleptic is closely related to the acceptance of the preparation of the patient, which is associated with the patients' comfort in taking the preparations. The organoleptic test for the four formulas of wound healing gel generated green colored gel that exudes characteristic herb odor, which was acceptable. The preparation's $\mathrm{pH}$ is one of the physical properties that affect its efficacy because it concerns the drug release process at the site of action.

Human skin is known to have a normal $\mathrm{pH}$ between 4.0 and 6.0 [26]. When an acute wound occurs, the skin's pH changes to a more alkaline level of about 7.4. Following that, naturally, the body will response by returning the acidity of the skin to restore the wound. During this, the environment surrounding the wounds will turn acidic. This acidic environment will inhibit the growth of bacteria, so infection does not occur. This is one of the activities in wound healing [27]. In order for a wound-healing preparation to assist this process, its $\mathrm{pH}$ must not be more than 6.0. Carbopol as the gelling agent, naturally has acidic $\mathrm{pH}$, so it needs to be neutralized to reach the targeted $\mathrm{pH}$ of formulation [28]. Triethanolamine (TEA) as the $\mathrm{pH}$ adjuster plays the important role to alkalize the gel's pH. When the TEA is added into the formulation, its $\mathrm{pH}$ increases. The $\mathrm{pH}$ test on all four formulas of Leucaena leaves extract gel generated the results of 6.0. These results indicate that the organoleptic and the $\mathrm{pH}$ of the preparation meet the standard requirements.

\section{Spreadability and viscosity test}

The other important aspects affecting the quality of topical preparations are spreadability and viscosity. These two factors affect the retention time of the preparation and its ease of application over the skin surface, which will finally have an impact on the effectiveness of the therapy [29]. Smaller spreadability means higher viscosity, which will make the preparation more difficult to apply on the skin. Too high spreadability, which means too low viscosity, is also undesirable because it will shorten the retention time on the skin surface. Thus, it is necessary to have the ideal dispersibility and viscosity values. The results of the spreadability and viscosity tests for the four wound healing gel formulas from Leucaena leaf extract, after $48 \mathrm{~h}$ of storage, are presented in table 2 . The spreadability ranges from $3.783-4.650 \mathrm{~cm}$ and the viscosity from $2433.333-3000$ cps. The test results show that the gel has good dispersibility and viscosity properties and is in accordance with the initial target, i.e., the spreadability of $3-5 \mathrm{~cm}$ and a viscosity of $2000-3000 \mathrm{cps}$.

As shown in table 2, Formula 1 and 3 have greater spreadability than other formulas. It's because Formula 1 and 3 contain less gelling agent $(1.0 \%$ of Carbopol). It is known that the lower concentration of Carbopol will increase the gel capability to spread [28]. On the other side, the viscosity of Formula 1 and 3 are lower than Formula 2 and 4. So, it can be said that when the concentration of the gelling agent is getting lower, its viscosity is decreasing, and its spreadability is increasing.

A viscosity shift test was performed to evaluate the gel's physical stability in a storage environment. The viscosity of the gel that had been stored for 1 mo was compared with the viscosity of the gel after $48 \mathrm{~h}$ of storage. The smaller the percentage shift in viscosity, the better the physical stability of the gel is.

Table 2: Test result of spreadability and viscosity

\begin{tabular}{lll}
\hline Formula & Spreadability $^{*}(\mathbf{c m})$ & Viscosity after 48 h of storage (cps) \\
\hline 1 & $4.650 \pm 0.265$ & $2433.333 \pm 57.735$ \\
2 & $3.983 \pm 0.416$ & $3000.000 \pm 0.000$ \\
3 & $4.100 \pm 0.350$ & $2466.667 \pm 57.735$ \\
4 & $3.783 \pm 0.029$ & $2750.000 \pm 0.000$ \\
\hline
\end{tabular}

${ }^{*}$ All values are mentioned in mean $\pm \mathrm{SD}(\mathrm{n}=3)$

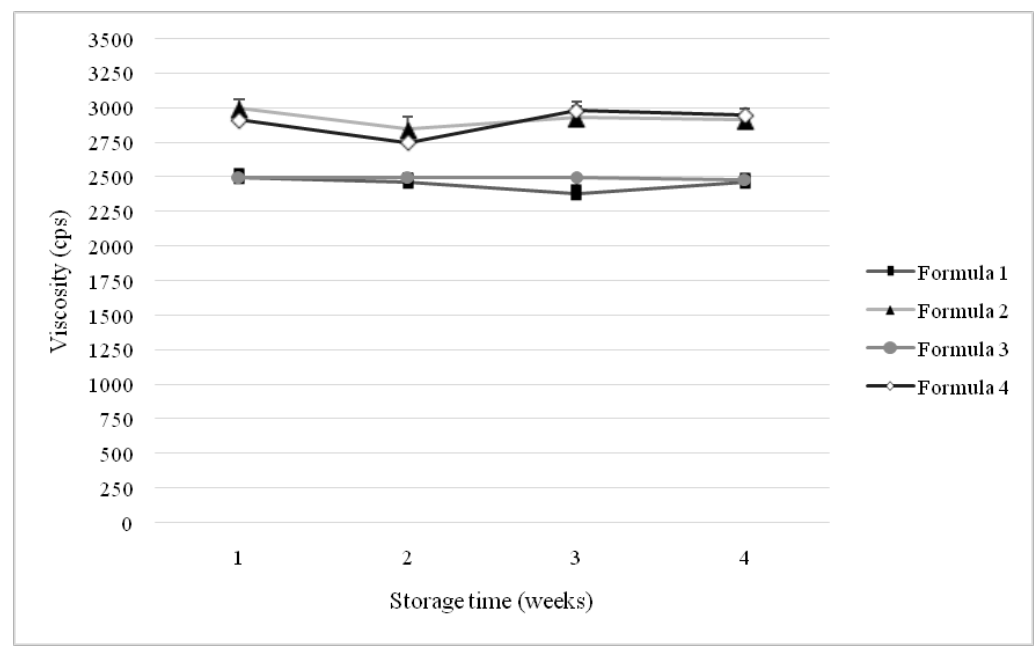

Fig. 1: Graphic of viscosity shift (all of the results are calculated as mean $\pm S D ; n=3$ )

Fig. 1 presents the general physical stability of the tested gel. Formula 2 and 4 have the same graphic profile; their viscosities tend to be higher than Formula 1 and 3. This is because Formula 2 and 4 contain higher Carbopol as their gelling agent $(1.5 \%)$ than Formula 1 and $3(1.0 \%)$. Therefore, according to the characteristics of the gelling agent: the greater the gelling agent concentration, the more viscous the preparation will be. Likewise, the viscosity profile of Formula 1 and 3 contains less gelling agent than the other two formulas, so that the viscosity is lower. In addition, from the graph, it can be seen that after the $3^{\text {rd }}$ week, all formulas have a relatively stable viscosity. From table 2, it is known that the four gel formulas have good physical stability, with the value of the viscosity shift of 
less than $10 \%$. The smallest shift in viscosity is shown by Formula 3, and the largest shift in viscosity is shown by Formula 4.

\section{Sterility test}

Topical preparations used for wound healing must meet certain sterility requirements [30]. It is related to product safety toward the exposed skin tissue because the wound is susceptible to infection by bacteria and other microorganisms. Therefore, it is necessary to ensure the product sterility in order not to harm the patients further. From table 3, it can be seen that, in general, the preparations meet the sterility requirements, even though non-sterile gels also exist, i.e., Formula 1 replication 3 and Formula 4 replication 3.

Table 3: Test result of gel's sterility

\begin{tabular}{llllll}
\hline Replication & Media control & F1 & F2 & F3 & - \\
\hline 1 & - & - & - & - & - \\
2 & - & - & - & - \\
3 & - & - & + & + \\
\hline
\end{tabular}

$(-)$ : the absence of bacteria growth, $(+)$ : the presence of bacteria growth

\section{Wound healing activity}

This test was conducted to determine the Leucaena leaf extract gel's ability to heal wounds in male Wistar rats. The test was carried out by applying the Leucaena leaf extract gel on the backs of the rats that had been injured. The rats were divided into six treatment groups, one rat each for Formula 1-4, one treatment group for the negative control (rats were injured without treatment), and one treatment group for the positive control (Bioplacenton ${ }^{\circledR}$ gel). The procedure was carried out in three repetitions that is by giving three wounds to each rat. Every day, the wound diameter was measured and given the gel until the wound was completely closed. Wound contraction was measured in the percentage reduction in wound area for each day.

Table 4: Wound closure percentage

\begin{tabular}{lllllll}
\hline Day & \multicolumn{2}{l}{ Wound closure (\%) } & & & \\
\cline { 2 - 7 } & Positive control & Negative control & F.1 & F.2 & F.3 & F.4 \\
\hline 0 & $0 \pm 0.000$ & $0 \pm 0.000$ & $0 \pm 0.000$ & $0 \pm 0.000$ & $0 \pm 0.000$ & $0 \pm 0.000$ \\
1 & $2.011 \pm 1.040$ & $8.303 \pm 1.748$ & $4.125 \pm 1.274$ & $2.887 \pm 3.046$ & $1.516 \pm 1.219$ & $1.870 \pm 3.221$ \\
3 & $20.341 \pm 9.178$ & $16.98 \pm 8.703$ & $28.785 \pm 3.006$ & $22.404 \pm 5.248$ & $17.378 \pm 11.780$ & $12.217 \pm 1.927$ \\
5 & $29.766 \pm 6.032$ & $24.677 \pm 1.353$ & $34.309 \pm 4.502$ & $32.818 \pm 1.588$ & $31.639 \pm 8.867$ & $27.768 \pm 7.959$ \\
7 & $42.816 \pm 3.484$ & $38.208 \pm 7.040$ & $48.638 \pm 1.518$ & $42.887 \pm 6.991$ & $41.731 \pm 9.394$ & $40.494 \pm 12.632$ \\
9 & $67.955 \pm 4.683$ & $44.068 \pm 5.138$ & $68.141 \pm 1.901$ & $63.030 \pm 4.266$ & $58.476 \pm 6.655$ & $60.878 \pm 7.435$ \\
11 & $83.295 \pm 9.717$ & $49.124 \pm 5.104$ & $95.611 \pm 7.602$ & $82.206 \pm 7.650$ & $88.536 \pm 19.857$ & $100.000 \pm 0.000$ \\
\hline
\end{tabular}

*All values are mentioned in mean $\pm \mathrm{SD}(\mathrm{n}=3)$

Table 4 shows that the negative control gave the lowest percentage of wound closure; it only reaches $49.124 \%$ on the $11^{\text {th }}$ day. Meanwhile, the biggest percentage of wound closure is shown by Formula 4, reaching $100 \%$ on the $11^{\text {th }}$ day. In addition, Formula 1,3 , and 4 even had a better percentage of wound closure than the positive control.

A statistical test was conducted to determine whether there was a significant difference in the percent value of wound closure between treatments. The normality test was carried out with the Shapiro Wilk test. It was known that abnormal data $\left({ }^{*} \mathrm{p}<0.05\right)$ existed, namely Formula 1, 3, and 4. Therefore, a non-parametric test, which the Kruskal Wallis test, was also conducted. This test aims to see the significant difference between the negative controls and the formula. The result obtained is *p-value $<0.05$, so it can be said that there are at least two groups that have significant mean differences. The test was continued with the two samples of the Wilcoxon test, and the results of the p-value were presented in table 5 .

Table 5: The result of wilcoxon test of the gels'wound healing activity

\begin{tabular}{ll}
\hline Treatments & p-value \\
\hline Formula 1: $(-)$ control & 0.0463 \\
Formula 2: $(-)$ control & 0.04953 \\
Formula 3: $(-)$ control & 0.1212 \\
Formula 4: $(-)$ control & 0.0369 \\
Formula 1: $(+)$ control & 0.2683 \\
Formula 2: $(+)$ control & 0.8273 \\
Formula 3: $(+)$ control & 0.5066 \\
Formula 4: $(+)$ control & 0.0369 \\
\hline
\end{tabular}

The Wilcoxon test data show that Formula 1, 2, and 4 have wound healing activity when compared to negative controls because they produce a ${ }^{*}$ p-value $<0.05$, while Formula 3 does not have wound healing activity. The comparison between the wound closure by each formula and the positive control shows that Formula 4 has a better percentage of wound closure because it had a ${ }^{*}$ p-value $<0.05$ (0.0369), while the other three formulas have the same percentage of wound closure as the positive control $(* p$-value $>0.05)$. This is because Formula 4 contains the highest amount of Carbopol as the gelling agent and Propylene glycol as the humectant. The development in wound management found that a moist environment would accelerate the wound healing process, especially in the reepithelization process [23]. Carbopol, when dispersed into water and its $\mathrm{pH}$ is neutralized, will form a rigid three-dimensional network that has the ability to absorb water, even to retain the water content that is absorbed in that network [24]. Propylene glycol is a humectant that has a vital role in topical preparations by maintaining skin moisture and increasing water absorption from the epidermis to the deeper parts of the skin (the dermis) [25]. Thus, the high concentration of Carbopol and Propylene glycol in Formula 4 can support the creation of a moist environment in the injured skin. This condition makes the fastest healing process compared to the other formulas. In addition, the high viscosity of Formula 4 is also considered to play a role in this. With its high viscosity, the retention time of the preparation on the skin surface is longer so that the absorption process of the drug into the skin tissue becomes more optimal.

A study that evaluated the phytochemical contents of Leucaena leaves proved that Leucaena leaves contain tannins, saponins, and flavonoids [22]. Tannins, saponins, and flavonoids are the ingredients of Leucaena leaves, which are believed to have wound healing activities that especially play a role in the process of forming new blood vessels [21]. Tannins are reported to have antiinflammatory and antibacterial activities that highly contribute to the wound healing process [31]. Flavonoid is one of the most common secondary metabolites found in Leucaena leaves [32]. Flavonoids have been shown to have activity in accelerating wound 
healing [33]. Saponins are reported to support the proliferation and formation of new blood vessels in the wound healing process [34]. Formula 4 is proven to have the best wound healing activity, because Formula 4 also contains the most Carbopol as a gelling agent and Propylene glycol as a humectant; compared to the other formulas, they can improve the humidity of the formula and maintain it. Leucaena leaf extract gel can heal wounds, possibly because of its antibacterial properties. Besides, it can also reduce pain, stimulate the formation of new blood vessels, and accelerate reepithelialization because it can provide a moist environment around the injured skin.

The formulation consideration plays an important role in wound healing preparation. The efficacy of the Leucaena leaf extract as a wound-healing agent is tightly associated with the selection of every material and excipient used in the formulation. Carbopol as the gelling agent, propylene glycol as the humectant, TEA as the alkalizing agent, methylparaben as the preservative, and distilled water as the vehicle can produce a gel with good characteristic that fulfills the pharmaceutical preparation specifications.

\section{CONCLUSION}

The formulation of Leucaena leaf extract in a gel preparation for wound healing has been proven to produce preparations that meet various quality requirements of pharmaceutical products, including $\mathrm{pH}$, viscosity, sterility, and wound healing activity. The gelling agent (Carbopol) and humectant (propylene glycol) used in this work have a significant role in the formulation; they can improve the humidity of the formula and maintain it. The moist environment can improve the wound healing process. Formula 4, with the greatest amount of gelling agent and humectant, has the best wound healing activity, even better than the positive control, while its physical and stability test results meet the requirements. Therefore, it can be concluded that Formula 4 is the best formula.

\section{ACKNOWLEDGEMENT}

None

\section{FUNDING}

Nil

\section{AUTHORS CONTRIBUTIONS}

All authors have contributed equally to this research article.

\section{CONFLICT OF INTERESTS}

The authors declared that no conflict of interest should arise concerning the authorship of this research article.

\section{REFERENCES}

1. Lei J, Sun L, Li P, Zhu C, Lin Z. The wound dressings and their applications in wound healing and management. Heal Sci J. 2019;13;3(662):1-8.

2. Dhivya S, Padma VV, Santhini E. Wound dressings-a review. Biomedicine. 2015;5(4):24-8.

3. Sorg H, Tilkorn DJ, Hager S, Hauser J, Mirastschijski U. Skin wound healing: an update on the current knowledge and concepts. Eur Surg Res. 2017;58(1-2):81-94. doi: 10.1159/000454919, PMID 27974711.

4. Vowden K, Vowden P. Wound dressings: principles and practice. Surgery (Oxford). 2014;32(9):462-7. doi: 10.1016/j.mpsur.2014.07.001.

5. FDA. FDA executive summary: classification of wound dressings combined with drugs. In: Meeting of the General and Plastic Surgery Devices Advisory Panel 2016. p. 1-83.

6. Saghazadeh S, Rinoldi C, Schot M, Kashaf SS, Sharifi F, Jalilian E, Nuutila K, Giatsidis G, Mostafalu P, Derakhshandeh H, Yue K, Swieszkowski W, Memic A, Tamayol A, Khademhosseini A. Drug delivery systems and materials for wound healing applications. Adv Drug Deliv Rev. 2018;127(Mar 1):138-66. doi: 10.1016/j.addr.2018.04.008, PMID 29626550.

7. Sarabahi S. Recent advances in topical wound care. Indian J Plast Surg. 2012;45(2):379-87. doi: 10.4103/09700358.101321, PMID 23162238.
8. Amirthalingam S, Yi KS, Ching LT, Mun NY. Topical antibacterials and global challenges on resistance development. Trop J Pharm Res. 2015;14(5):919-24. doi: 10.4314/tjpr.v14i5.24.

9. Sartinah A, Astuti P. Wahyuono S. Isolasi dan Identifikasi Senyawa Antibakteri dari Daun Petai Cina (Leucaena leucocephala (Lam.) de Wit.). Maj Obat TraDIS. 2010;15(3).

10. Zayed MZ, Samling B. Phytochemical constituents of the leaves of Leucaena leucocephala from Malaysia. Int J Pharm Pharm Sci. 2016;8(12):174-9. doi: 10.22159/ijpps.2016v8i12.11582.

11. Chatchanayuenyong R, Sujayanont P. Evaluation of the antiproliferation and anti-migration effects of Leucaena leucocephala and Dolichandrone serrulata ethanolic extracts against human cervical cancer cell line. Phcog Mag. 2020;16(68). doi: 10.4103/pm.pm_327_19.

12. Eritriana RE, Rosiana AH, Tantri Y, Ekayanti E, Lamtoro EED. (Leucaena leucocephala L.) sebagai Alternatif Penyembuhan Luka Abrasi. J Penelit Kesehat Suara Forikes. 2019;10(2):290-4.

13. Budiman A, Muharam MAC, Maulida AC, Aulifa DL. Formulation of gel from Gynura segetum extract and its activity on burn wound healing. Int J App Pharm. 2021;13(2):269-71. doi: 10.22159/ijap.2021v13i2.40438.

14. Widyaningsih W, Salamah N, Maulida QF. Gel formulation of ethanol extract of mangosteen peel (Garcinia mangostana L.) as a medication for burns in Wistar rats. Indones J Heal J 2016;8(2):110-7.

15. Morsy MA, Abdel-Latif RG, Nair AB, Venugopala KN, Ahmed AF, Elsewedy HS, Shehata TM. Preparation and evaluation of atorvastatin-loaded nanoemulgel on wound-healing efficacy. $\begin{array}{lll}\text { Pharmaceutics. } & \text { 2019;11(11):1-15. }\end{array}$ 10.3390/pharmaceutics11110609, PMID 31766305.

16. Ermawati DE, Ramadhani CI. Formulation of anti-acne gel of moringa oleifera, l. ethanolic extract and antibacterial test on staphylococcus epidermidis. Majalah Farmaseutik 2020;16(2):154-62. doi: 10.22146/farmaseutik.v16i2.50319.

17. Sanders ER. Aseptic laboratory techniques: plating methods. J Vis Exp. 2012;63(63):e3064. doi: 10.3791/3064, PMID 22617405.

18. Lodhi S, Vadnere GP. Relevance and perspectives of experimental wound models in wound healing research. Asian J Pharm Clin Res. 2017;10(7):68-75.

19. Liu H, Lin S, Xiao D, Zheng X, Gu Y, Guo S. Evaluation of the wound healing potential of Resina Draconis (Dracaena cochinchinensis) in animal models. Evid Based Complement Alternat Med. 2013;2013:709865. doi: 10.1155/2013/709865, PMID 23762154.

20. Sabat PK, Pradhan SP, Patro R. Evaluation of excisional and incisional wound healing activity of electrohomeopathic drug (spagyric essence) green electricity in rats. Int J Pharm Pharm Sci. 2020;12(10):72-5. doi: 10.22159/ijpps.2020v12i10.38674.

21. Fitrian A. Efek angiogenesis gel ekstrak daun lamtoro (Leucaena leucocephala) pada Luka Insisi tikus. JBP. 2018;20(1):22. doi: 10.20473/jbp.v20i1.2018.22-32.

22. Deivasigamani R. Phytochemical analysis of Leucaena leucocephala on various extracts. J Phytopharmacol. 2018;7(6):480-2. doi: 10.31254/phyto.2018.7605.

23. Lantis JC, Paredes JA. Topical wound care treatment and indications for their use. New York: international springer publishing. Agriculturists; 2018. p. 281-304.

24. R Varges P, M Costa C, S Fonseca B, F Naccache M, De Souza Mendes P. Rheological characterization of carbopol ${ }^{\circledR}$ dispersions in water and in water/glycerol solutions. Fluids. 2019;4(1):1-20. doi: 10.3390/fluids4010003.

25. Purnamawati S, Indrastuti N, Danarti R, Saefudin T. The role of moisturizers in addressing various kinds of dermatitis: a review. Clin Med Res. 2017;15(3-4):75-87. doi: 10.3121/cmr.2017.1363, PMID 29229630.

26. Jones EM, Cochrane CA, Percival SL. The effect of $\mathrm{pH}$ on the extracellular matrix and biofilms. Adv Wound Care. 2015;4(7):431-9. doi: 10.1089/wound.2014.0538, PMID 26155386.

27. Baron JM, Glatz M, Proksch E. Optimal support of wound healing: new insights. Dermatology. 2020;236(6):593-600. doi: 10.1159/000505291, PMID 31955162. 
28. Safitri FI, Nawangsari D, Febrina D. Overview: application of carbopol 940. In: Gel international conference on health and medical sciences; 2020. p. 80-4.

29. USP. Topical and transdermal drug products. The U State Pharmacopeial/Natl Formul Pharmacopeial Forum; 2009. p. 750-64.

30. World Health Organization (WHO). Topical semi-solid dosage forms. Int Pharmacopoeia; 2019. p. 2-4

31. Sieniawska E, Baj T. Tannins. In: Pharmacognosy: fundamentals, applications and strategy. Elsevier Inc; 2017. p. 199-232.
32. Zarina Z, Ghazali CMR, Sam ST. Characterization analysis for leaves of Leucaena leucocephala by using phytochemical screening assay. AIP Conf Proc; 2017.p. 1885.

33. Aslam MS, Ahmad MS, Riaz H, Raza SA, Hussain S, Qureshi OS. Role of flavonoids as wound healing agent. PhytochemicalsSource Antioxid Role Dis Prev Integr; 2018. p. 95-102.

34. Majewska I, Gendaszewska Darmach E. Proangiogenic activity of plant extracts in accelerating wound healing - a new face of old phytomedicines. Acta Biochim Pol. 2011;58(4):449-60. doi: 10.18388/abp.2011_2210, PMID 22030557. 